\title{
A glimpse into the active site of a group II intron and maybe the spliceosome, too
}

\author{
KWAKU T. DAYIE ${ }^{1,2,3}$ and RICHARD A. PADGETT ${ }^{1}$ \\ ${ }^{1}$ Department of Molecular Genetics, Lerner Research Institute, Cleveland Clinic, Cleveland, Ohio 44195, USA \\ ${ }^{2}$ Center for Structural Biology, Lerner Research Institute, Cleveland Clinic, Cleveland, Ohio 44195, USA \\ ${ }^{3}$ Department of Chemistry and Biochemistry, University of Maryland, College Park, Maryland 20742, USA
}

\begin{abstract}
The X-ray crystal structure of an excised group II self-splicing intron was recently solved by the Pyle group. Here we review some of the notable features of this structure and what they may tell us about the catalytic active site of the group II ribozyme and potentially the spliceosome. The new structure validates the central role of domain $V$ in both the structure and catalytic function of the ribozyme and resolves several outstanding puzzles raised by previous biochemical, genetic and structural studies. While lacking both exons as well as the cleavage sites and nucleophiles, the structure reveals how a network of tertiary interactions can position two divalent metal ions in a configuration that is ideal for catalysis.
\end{abstract}

Keywords: RNA catalysis; RNA structure; magnesium ion binding; two metal ion hypothesis

\section{INTRODUCTION}

The puzzling discovery of the split nature of eukaryotic genes and the need to remove introns via RNA splicing immediately posed two fascinating questions: How is it done? And how did it arise? In the early 1980s, the astounding discovery by Tom Cech (Kruger et al. 1982) and Sidney Altman (Guerrier-Takada et al. 1983) that RNAs can function as enzymes or ribozymes opened the possibility that RNA might hold the key to answering both questions. Within a few years it was established that there were two types of introns that were able, in many cases, to remove themselves from RNA transcripts without the need for protein cofactors. These were named the group I and group II introns (Michel and Dujon 1983). In parallel work, the introns found in most nuclear genes of eukaryotes were found to be removed through the action of the spliceosome, an enormous complex composed of five small nuclear RNAs and hundreds of proteins. In spite of these differences, the existence of self-splicing intron ribozymes quickly led to the hypothesis that pre-mRNA introns and

Reprint requests to: Richard A. Padgett, Department of Molecular Genetics, Lerner Research Institute, Cleveland Clinic, 9500 Euclid Avenue, Cleveland, OH, 44195, USA; e-mail: padgetr@ccf.org; fax: (216) 444-0512; and Kwaku T. Dayie, Department of Chemistry and Biochemistry, Center for Biomolecular Structure and Organization, University of Maryland, 1115 Biomolecular Sciences Building \#296, College Park, MD 20742-3360, USA; e-mail: dayie@umd.edu; fax: (301) 314-9121.

Article published online ahead of print. Article and publication date are at http://www.rnajournal.org/cgi/doi/10.1261/rna.1154408. the spliceosome are evolutionary descendents of self-splicing introns. Since we cannot rewind the history of eukaryotes to watch such evolution happen and there have not, so far, been found any clear examples of intermediate steps in such a process, we are left with comparing the structures and functions of the existing molecules to evaluate this hypothesis.

Group I introns splice via a two-step phosphoryl transfer reaction using an exogenous guanosine as a cofactor (Kruger et al. 1982), a mechanism that does not resemble the process of spliceosomal splicing. The group II introns, on the other hand, splice via a different two-step mechanism using an internal adenosine to initiate the self-splicing reaction (Peebles et al. 1986; van der Veen et al. 1986). Remarkably, this is the same overall mechanism used by the spliceosome (Fig. 1). Indeed, subsequent work has demonstrated a complete concordance in the mechanistic details of group II intron and spliceosomal splicing (for review, see Pyle and Lambowitz 2006). The apparent similarities also extend to critical and highly conserved RNA elements, as we discuss below.

To fully understand and evaluate the meaning of these apparent similarities in structure and function requires detailed structural information. However, until now, there have been no high-resolution structures of either the group II intron or the spliceosome. Following the spectacular structures of the group I introns published more than 3 years ago (Adams et al. 2004; Guo et al. 2004; Golden et al. 2005; Stahley and Strobel 2005), the group of Anna Marie Pyle 


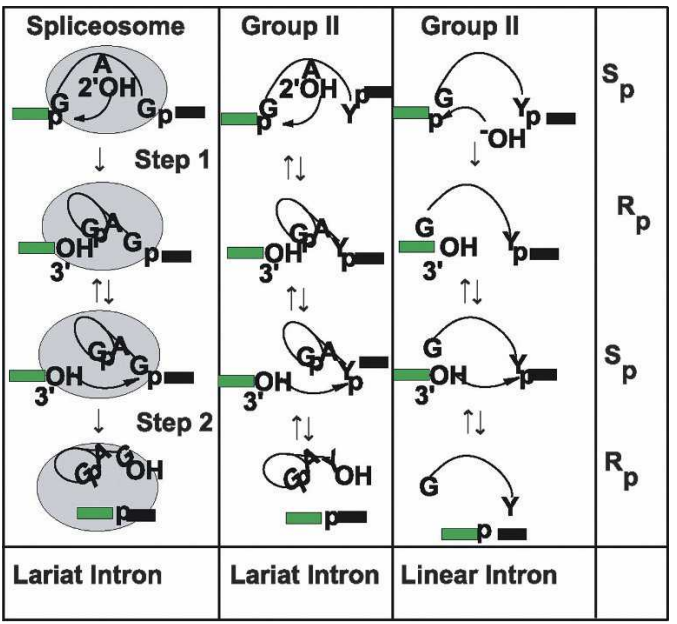

FIGURE 1. Parallels between the splicing mechanisms of the spliceosome and group II introns. (Left panel) spliceosomal pre-mRNA splicing. Group II intron splicing using the branching (middle panel) and hydrolytic pathways (right panel) are depicted, together with the diastereomeric preferences ( $R p$ or $S p$ ) for each step of the splicing reactions. A conformational rearrangement is required between catalytic steps 1 and 2 .

now provides an intriguing view into the catalytic core of a group II intron (Toor et al. 2008). This self-splicing intron is from the gram-positive bacterium Oceanobacillus iheyensis (Oi) isolated from the extreme salt, $\mathrm{pH}$, and highpressure environment of the deep sea sediments of the hydrothermal vent communities on the Japanese Nansei Islands (Lu et al. 2001; Takami et al. 2002; Takaki et al. 2004). The new X-ray crystallographic structure provides a clarifying lens through which to view several decades of biochemical and biophysical data on group II introns but also poses a number of very important unanswered questions. In this perspective we summarize our current knowledge of group II introns, review the salient biochemical predictions in light of this new three-dimensional (3D) structure, and outline some of the areas for future study to help elucidate the structural basis of the group II intron catalysis. Finally, we touch on the implications of this structure for the catalytic mechanism of spliceosomal splicing and, in particular, the relationships of the highly conserved RNA elements in these two splicing systems.

Group II introns are composed of six discrete elements or domains numbered I through VI. Domains I and V are essential for any ribozyme activity while domain VI contributes the adenosine residue used in the branching pathway of splicing (Fig. 1). Domains II and III enhance the catalysis of splicing while domain IV, which usually contains a protein coding segment, is not involved in catalysis. Domain $\mathrm{V}$ is a short RNA hairpin containing a bulge region that is essential for catalysis (Peebles et al. 1995). It is the most highly conserved element of group II introns and can function in trans in a two-part ribozyme system (Jarrell et al. 1988). Domain V shares structural and sequence similarities with the essential and conserved intramolecular stem-loop element of the U6 and U6atac snRNAs of the spliceosomes. In fact, these elements can be made functionally interchangeable (Shukla and Padgett 2002). As a consequence, domain V and the U6/U6atac stem-loop have been the subjects of a significant body of biochemical and structural investigation. A frustrating outcome from these studies is that the structures of the isolated elements provided limited insight into the biochemistry (Zhang and Doudna 2002; Sigel et al. 2004; Gumbs et al. 2006; Seetharaman et al. 2006). The structure of domain V in its bound state now shows how it likely works.

\section{THE 3D ARCHITECTURE OF THE CATALYTIC SITE}

The $O i$ intron belongs to the group IIC class of introns that have a number of significant differences compared to the extensively characterized group IIA and group IIB introns. For the most part, the overall organization and structure is similar in all these classes. Features in the structure that likely differ are highlighted below.

The crystal structure solved by Toor et al. (2008) is of a truncated form of the intron product after undergoing both steps of splicing. Thus, both the exons and the cleavage sites are not present. In addition, domain IV has been replaced by a hairpin, and domains II, III, and VI have been truncated. These deletions remove the $\eta-\eta^{\prime}$ interaction between domains II and VI (Fig. 2A) with potential effects on the structure. Perhaps as a result, the branch site donating domain VI is not resolved in the structure. Alternatively, domain VI may not fold into the structure since the $\mathrm{O} i$ intron can only splice in vitro via the nonbranching hydrolytic pathway (Fig. 1, right). Fortunately, the remainder of the intron is a highly folded structure with a web of entangled tertiary interactions, most of them predicted but also with a few surprises.

The biggest surprise is how contorted the domain $\mathrm{V}$ structure is compared to the free structure in solution. This was not completely unexpected, however, as other workers (Costa et al. 2000; Gumbs et al. 2006) had predicted that the actively bound domain $\mathrm{V}$ conformer would have to undergo large conformational changes to adapt to the rest of the intronic elements, facilitated perhaps by the flexibility of the bulge region (Eldho and Dayie 2007).

The structure shows that domain I encases domain $\mathrm{V}$ on either side, forms a roof above it, and leaves a coaxially stacked domain III and domain IV as the floor or foundation such that domain $\mathrm{V}$ is centrally oriented at the very heart of the catalytic machinery (Fig. 2). Starting from the $5^{\prime}$ end of the intron, helices I(i) and I(ii) from domain I coaxially stack on domain II, and in turn, the base of domain II forms a GNRA receptor-tetraloop interaction with the GCGA tetraloop (TL) within stem IC via the expected $\theta-\theta^{\prime}$ interaction. The stem of the IC domain latches onto this domain II receptor as it runs the length of 
A

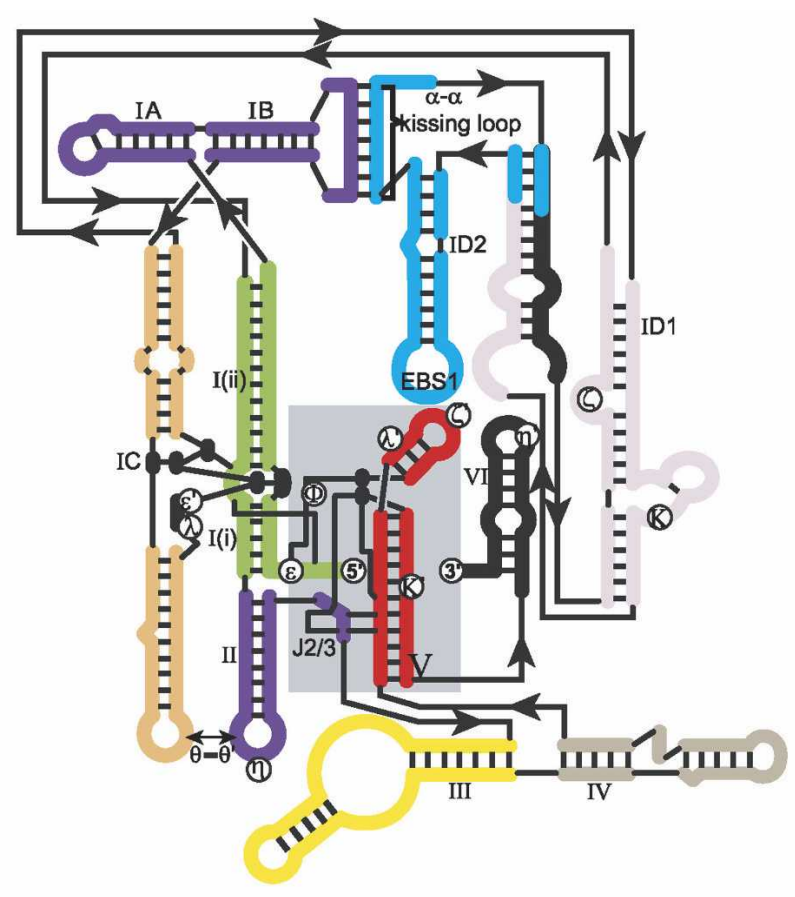

B

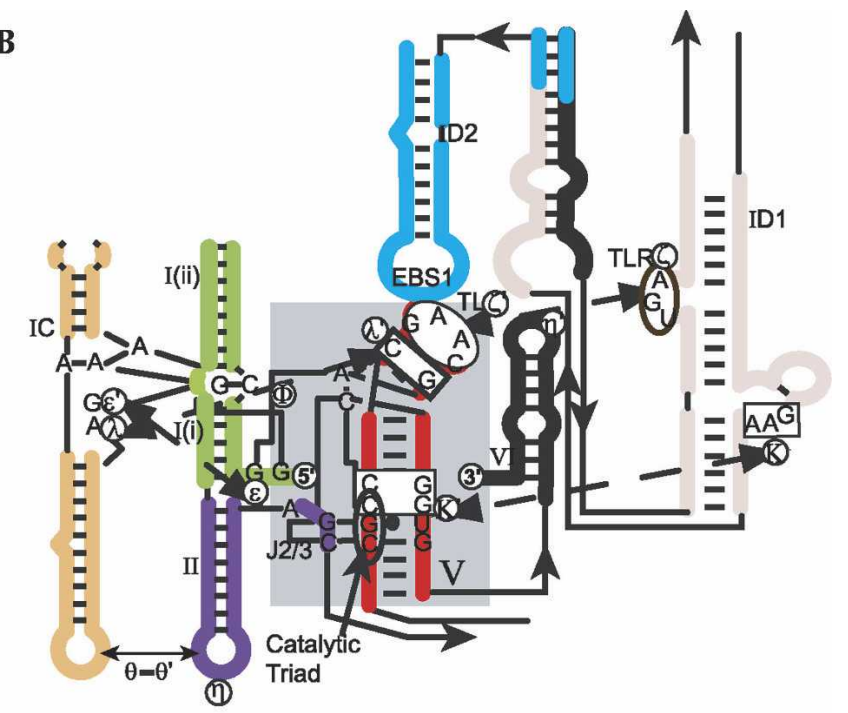

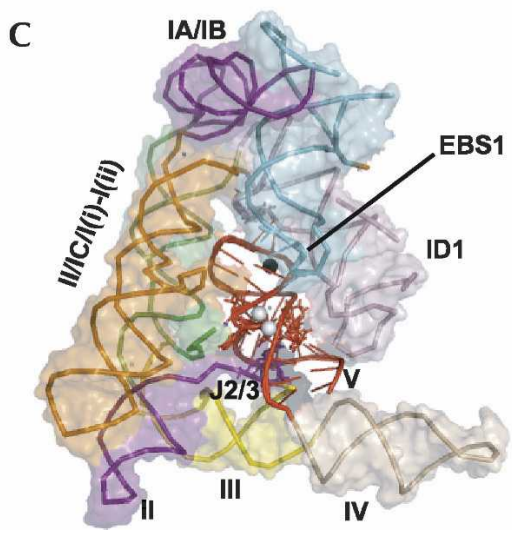

FIGURE 2. Domain V is at the center of the group II intron structure. (A) Revised secondary structure of the group II intron based on the crystal structure of the $O$. iheyensis intron. The breakdown of the domain structure reflecting Watson-Crick tertiary interactions and coaxial stacking is depicted and the $5^{\prime}$ and $3^{\prime}$ ends of the intron are circled. The active site centered on domain $\mathrm{V}$ is depicted in the shaded box. $(B)$ The region centered on domain $\mathrm{V}$ is expanded to depict details of long-range interactions involving conserved regions of domain $\mathrm{V}$ and the other intronic elements. These include the internal bulge adenosine in domain $\mathrm{V}$ that forms a $\Phi$ interaction with $\varepsilon$ element in domain $1-\mathrm{I}(i)$; the tetraloop within domain $\mathrm{V}$ that docks into the TLR via the $\zeta-\zeta^{\prime}$ interaction; the upper helix of domain $\mathrm{V}$ that interacts with the IC element in domain I via the $\lambda-\lambda^{\prime}$ interaction; and the lower helix of domain $V$ that interacts with the ID1 element in domain I via the K-K' interaction. The $\eta-\eta^{\prime}$ interaction shown here between domains II and VI is absent in the crystallized construct. (C) Domains I, II, III, and IV, shown here as colored surfaces corresponding to the colors in $A$ with the structures outlined as ribbon, completely encase domain $\mathrm{V}$. Domain $\mathrm{V}$ is shown as a red cartoon with Watson-Crick pairings outlined. The J2/3 element is shown in purple and the EBS1 element in cyan. The catalytically implicated $\mathrm{Mg}^{2+}$ ions are presented as gray spheres and a third $\mathrm{Mg}^{2+}$ ion that binds to the tetraloop is depicted as a black sphere. The $\mathrm{K}^{+}$ions are omitted for clarity.

the intron structure parallel to the I(i) -I(ii) helices. At the top, both structures are held in place by horizontal coaxially stacked helices from stems IA and IB. The latter structures are held in place by a kissing-loop interaction mediated by the previously predicted $\alpha-\alpha^{\prime}$ interaction. This highly conserved kissing interaction enables the exon binding site 1 (EBS1) and the $\zeta^{\prime}$ loop element to dangle down to the TL of domain $\mathrm{V}$.
Unique to the group IIC introns, the tetraloop-tetraloop receptor (TL-TLR) interaction involves a single bulged guanosine within the receptor that stacks on top of domain V's trinucleotide AAC within the GAAC tetraloop. EBS1 also appears to make intimate contacts with domain V's tetraloop. This contrasts with what is expected for the group IIA or IIB TL-TLR interactions as well as similar interactions seen in the group I introns and the hammerhead 
ribozyme (Pley et al. 1994; Costa and Michel 1995; Cate et al. 1996a,b; Adams et al. 2004; Golden et al. 2005). In these cases the receptor is an 11-nucleotide (nt) motif wherein the first adenosine in the TL forms a hydrogen bond to a reverse Hoogsteen U:A pair, the second adenosine forms a hydrogen bond using its $2^{\prime}$-hydroxyl, and the third adenosine forms a hydrogen bond with a $\mathrm{C}: \mathrm{G}$ base pair of the TLR. It is not clear if the EBS1 interaction is unique to IIC introns or a consequence of the construct used in the structure determination, which lacks exonic elements. Thus, this part of the structure is likely to be the most different in group IIA/IIB introns or in the transition state structure or both.

\section{TWO METAL IONS IN THE ACTIVE SITE?}

The large ribozymes including group I and group II introns appear to require divalent metal ions for their catalytic activity. The locations and number of these essential ions and the precise roles that each plays in the catalytic mechanism have been a central theme in their study. Comparison with protein polymerase and phosphatase active sites (Steitz and Steitz 1993), computational predictions (Uchimaru et al. 1993), and metal specificity switch experiments (Chanfreau and Jacquier 1994; Sontheimer et al. 1999; Gordon et al. 2000a,b, 2007; Gordon and Piccirilli 2001) have led to the two-metal ion hypothesis for phosphoryl transfer reactions in the group II introns; a similar mechanism is expected for group I introns (Stahley and Strobel 2006) and perhaps the spliceosome as well (Steitz and Steitz 1993).

In addition to the tetraloop discussed above, domain $\mathrm{V}$ has two structural elements that have long been implicated in the catalytic activity of the ribozyme (Chanfreau and Jacquier 1994; Boulanger et al. 1995; Peebles et al. 1995; Abramovitz et al. 1996; Schmidt et al. 1996). A highly conserved sequence, AGC (or CGC as in the present case), which has been dubbed the "catalytic triad" is positioned near the 5 ' end of domain $\mathrm{V}$, and an asymmetrical bulge is located toward the center of domain V. Previous structural work had predicted specific magnesium ions at the junction of the first and second nucleotides of the catalytic triad (Seetharaman et al. 2006) as well as in the bulge region (Sigel et al. 2004; Seetharaman et al. 2006). Initial X-ray crystal and NMR solution structures of the aI5 $\gamma$ intron domain $\mathrm{V}$ in isolation did not reveal a magnesium ion binding site within the catalytic triad (Zhang and Doudna 2002; Sigel et al. 2004), but a later and more detailed NMR study found specific binding to the minor groove face of the adenosine of the triad at the N7 position (Seetharaman et al. 2006) in the PL intron (Costa et al. 1997). The prediction of three divalent metal ion binding sites (Fig. 2C, tetraloop, bulge, and AGC triad) has been borne out by this new X-ray structure. Importantly, the two likely catalytic metal ions identified as M1 and M2 are separated by $3.9 \AA$ and positioned by the bulge and triad nonbridging phosphoryl oxygens (Fig. 3). This distance and geometry coincide nicely with the predictions of the two metal ion hypothesis. Thus, this structure appears to fully validate the idea that domain $\mathrm{V}$ is the catalytic metal binding platform for the group II introns and that it likely serves to present these ions to both the $5^{\prime}$ and $3^{\prime}$ splice sites (Fig. 4).

\section{CATALYTIC TRIAD MISNOMER RESOLVED}

A puzzling observation that called into question the designation of the AGC trinucleotides as a catalytic triad has now been resolved (Boulanger et al. 1995; Peebles et al. 1995; Seetharaman et al. 2006). Using very high-resolution $\mathrm{NMR} \mathrm{Mg}^{2+}$ titration of domain $\mathrm{V}$ from PL, none of the guanosine functional groups probed (ribose $\mathrm{C1}^{\prime}$, base $\mathrm{C} 8$, aromatic N7 and N9) were found to be responsive to $\mathrm{Mg}^{2+}$. A previous X-ray structural analysis also failed to uncover any divalent ion binding within the AGC triad region (Zhang and Doudna 2002). Lack of responsiveness of the guanosine's $\mathrm{N} 7$ to $\mathrm{Mg}^{2+}$ was particularly perplexing given previous expectations that catalysis likely proceeds with N7 and $\mathrm{O} 6$ groups on guanosine because modification of either O6 or N7 destroyed all reactivity (Konforti et al. 1998). The new X-ray structure now provides a nice resolution of this conundrum: Two residues within the highly conserved junction region between domains 2 and 3 (J2/3) stack underneath the bulge and form a base triple directly with the three nucleotides of the triad in domain V (Fig. 3). These interactions position one bulge and two triad residues to form inner sphere contacts with the critical $\mathrm{Mg}^{2+}$ ions via nonbridging oxygens. Thus the abolition of

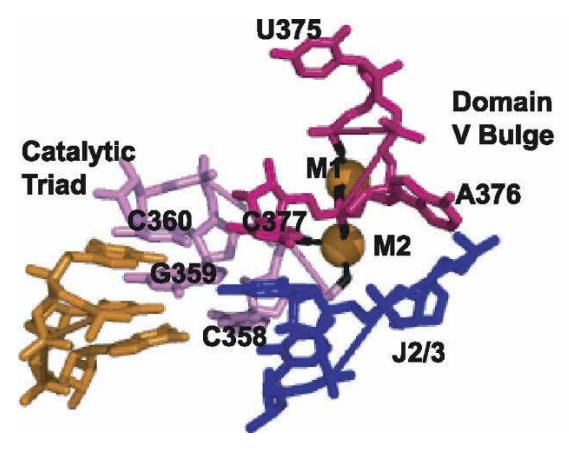

FIGURE 3. Details of the catalytic triplex structure. The conserved linker element J2/3 (blue) forms a base triple interaction with catalytic triad elements $\left(5^{\prime}\right.$-triad nucleotides in violet and the $3^{\prime}$-triad nucleotides in orange) and stacks beneath the bulge nucleotides (pink) to position the binuclear metal cluster (orange spheres) for splicing chemistry. The active site nonbridging oxygens are highlighted in black. 


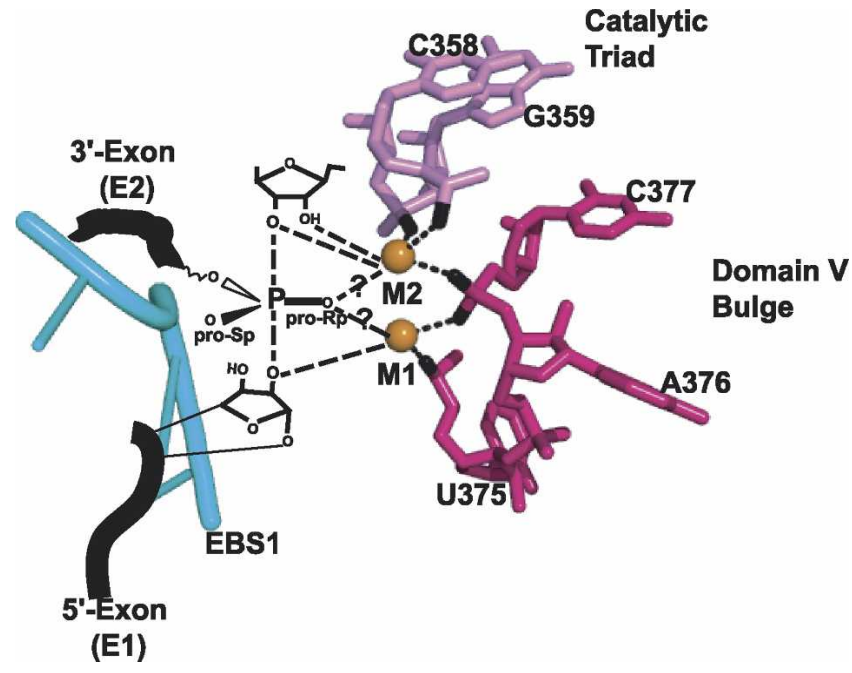

FIGURE 4. Model of the active site of the group II intron during the second catalytic step (nucleophilic attack by the $3^{\prime}-\mathrm{OH}$ of the $5^{\prime}$ exon on the $3^{\prime}$ splice junction) of self-splicing showing biochemically implicated catalytic metal ions and the active site oxygens biochemically implicated in catalysis. The metal binding residues from the catalytic triad (violet) C358, G359, and bulge (pink) C377, and upper helical residue (pink) U375 from the O. iheyensi intron are shown. The cleavage site and the positioning of the $5^{\prime}$ exon by the EBS1 element were modeled and are not a part of the X-ray structure.

catalytic activity by the modification of $\mathrm{O} 6$ and $\mathrm{N} 7$ atoms in guanosine is likely to be an indirect effect that weakens or abrogates this base-triple interaction and not because $\mathrm{Mg}^{2+}$ binds to those sites directly.

Finally, in vivo the six most highly conserved paired nucleotides in the lower helix of domain $\mathrm{V}$ display an asymmetry in which the nucleotides on the $3^{\prime}$ side of the helix, which base pair to the triad nucleotides, appear to be less important than the triad nucleotides for function (Boulanger et al. 1995; Peebles et al. 1995). The X-ray structure provides a likely resolution of this puzzling observation. The nucleotides base-paired to the triad are further away from the stabilizing interactions. They function to hold the triad in a hydrogen-bonding configuration that is optimal for stabilizing the catalytic locus.

\section{UNANTICIPATED BULGE, TRIAD, AND J2/3 CATALYTIC TRIPLEX}

What was largely unpredicted, although not completely unanticipated, by biochemical data and sequence analysis is the base-triple interaction involving the AGC (CGC) triad, the conserved nucleotides in $\mathrm{J} 2 / 3$, and the bulge as described above. Previous photocross-linking studies had correctly placed the purine rich J2/3 strand antiparallel to the lower helical elements in domain V (Podar et al. 1998). That study had correctly predicted that the highly conserved $G$ and A residues of J2/3 approach the lower helix of domain $\mathrm{V}$ approximately perpendicular to the helical axis and encounter the $5^{\prime}$ strand of domain $\mathrm{V}$ before the $3^{\prime}$ strand in the $5^{\prime}$ to $3^{\prime}$ direction of $\mathrm{J} 2 / 3$ residues and in close proximity to the conserved trimer $5^{\prime}$-AGC that is paired to $5^{\prime}$-GUU (Fig. 2B). This insightful prediction is nicely confirmed by the X-ray crystal structure. What was unanticipated is the bulge residue C377 forming a base triple with the C360-G383 Watson-Crick base pair in the lower helix (Figs. 3 and 4).

\section{CONNECTION WITH SPLICEOSOME IS MORE THAN SKIN DEEP}

The great many similarities between group II and spliceosomal introns strongly point to a common evolutionary origin. A frequent suggestion is that an early eukaryotic progenitor was invaded by one or more group II introns, which became inserted throughout the genes of this organism. Over subsequent time, the functions of the cisacting sequence elements of these introns were taken over by trans-acting small RNAs while retaining the fundamental catalytic mechanism of the self-splicing introns. This idea forms part of the basis for the popular idea that the spliceosome, like the ribosome, is a ribozyme at heart.

So, does this new group II intron structure fit in with what we know about the spliceosome and could we be seeing something similar to the heart of this huge RNA/ protein complex? Happily, much of the spliceosome data is fully compatible with the catalytic mechanism suggested by this group II crystal structure. The conserved AGC triad and bulge of U6 (and U6atac) snRNA are similarly postioned to the triad and bulge of domain V. Mutations in yeast of the first two positions of the U6 triad are lethal or cause strong growth defects and, curiously, just like in domain $\mathrm{V}$, the central position of the U6 triad must be a purine (Boulanger et al. 1995; Peebles et al. 1995; Hilliker and Staley 2004). A phosphate oxygen in the bulge of U6 (adjacent to U80 in yeast U6) has been shown to bind a key metal ion in the spliceosome (Yean et al. 2000) in a fashion probably similar to the domain $\mathrm{V}$ bulge residue (Huppler et al. 2002; Sigel et al. 2004; Seetharaman et al. 2006). A second highly conserved motif found in both U6 and U6atac snRNAs is the AGAG sequence immediately adjacent to residues that contact the $5^{\prime}$ splice site. This has been suggested to play a similar role to the conserved AGA trimer in the group II J2/3 region that forms part of the metal binding platform along with domain $\mathrm{V}$ (de Lencastre and Pyle 2008). These regions of U6 snRNA are complexed with U2 snRNA in the catalytically active form of the spliceosome and, indeed, engineered RNA constructs comprised of not much more than these regions show splicinglike ribozyme activity (Valadkhan et al. 2007). From this, it seems fair to conclude that the U6/U2 complex contains atomic groups that can be arranged in a very similar way to that seen in the group II intron to provide a metal binding platform that could carry out the catalytic reactions of 
splicing. The spliceosome is indeed looking more and more like a ribozyme.

\section{FUTURE DIRECTIONS}

This crystal structure is significant in bringing us closer to understanding the structural basis for catalysis in group II introns but is still incomplete. The construct used for crystallization lacks both of the exons while domain VI, which includes the intronic adenosine nucleophilic $2^{\prime}-\mathrm{OH}$, is not resolved in the structure. What is visible is a divalent metal ion binding platform that can rearrange phosphodiester bonds brought into the correct geometry with it. Future structures will show us how this is accomplished and how the active site is rearranged between the two steps of the complete splicing reaction. We already have hints that it will likely involve conformational changes in domain $\mathrm{V}$ likely facilitated by the flexibility of the bulge region (Eldho and Dayie 2007). For the spliceosome, a fascinating question is which of these roles are filled by proteins or RNA elements or both.

\section{ACKNOWLEDGMENTS}

RNA research in our laboratories is supported by NIH GM077326 (K.T.D.) and GM079527 (R.A.P.). We are grateful to Dave Schumick for help with preparing Figure 2A.

\section{REFERENCES}

Abramovitz, D.L., Friedman, R.A., and Pyle, A.M. 1996. Catalytic role of 2 prime-hydroxyl groups within a group II intron active site. Science 271: 1410-1413.

Adams, P.L., Stahley, M.R., Gill, M.L., Kosek, A.B., Wang, J., and Strobel, S.A. 2004. Crystal structure of a group I intron splicing intermediate. RNA 10: 1867-1887.

Boulanger, S.C., Belcher, S.M., Schmidt, U., Dib-Hajj, S.D., Schmidt, T., and Perlman, P.S. 1995. Studies of point mutants define three essential paired nucleotides in the domain 5 substructure of a group II intron. Mol. Cell. Biol. 15: 4479-4488.

Cate, J.H., Gooding, A.R., Podell, E., Zhou, K., Golden, B.L., Kundrot, C.E., Cech, T.R., and Doudna, J.A. 1996a. Crystal structure of a group I ribozyme domain: Principles of RNA packing. Science 273: 1678-1685.

Cate, J.H., Gooding, A.R., Podell, E., Zhou, K., Golden, B.L., Szewczak, A.A., Kundrot, C.E., Cech, T.R., and Doudna, J.A. 1996b. RNA tertiary structure mediation by adenosine platforms. Science 273: 1696-1699.

Chanfreau, G. and Jacquier, A. 1994. Catalytic site components common to both splicing steps of a group II intron. Science 266: $1383-1387$.

Costa, M. and Michel, F. 1995. Frequent use of the same tertiary motif by self-folding RNAs. EMBO J. 14: 1276-1285.

Costa, M., Fontaine, J.M., Loiseaux-de Goer, S., and Michel, F. 1997. A group II self-splicing intron from the brown alga Pylaiella littoralis is active at unusually low magnesium concentrations and forms populations of molecules with a uniform conformation. J. Mol. Biol. 274: 353-364.

Costa, M., Michel, F., and Westhof, E. 2000. A three-dimensional perspective on exon binding by a group II self-splicing intron. EMBO J. 19: 5007-5018. de Lencastre, A. and Pyle, A.M. 2008. Three essential and conserved regions of the group II intron are proximal to the $5^{\prime}$-splice site. RNA 14: 11-24.

Eldho, N.V. and Dayie, K.T. 2007. Internal bulge and tetraloop of the catalytic domain 5 of a group II intron ribozyme are flexible: Implications for catalysis. J. Mol. Biol. 365: 930-944.

Golden, B.L., Kim, H., and Chase, E. 2005. Crystal structure of a phage Twort group I ribozyme-product complex. Nat. Struct. Mol. Biol. 12: 82-89.

Gordon, P.M. and Piccirilli, J.A. 2001. Metal ion coordination by the AGC triad in domain 5 contributes to group II intron catalysis. Nat. Struct. Biol. 8: 893-898.

Gordon, P.M., Sontheimer, E.J., and Piccirilli, J.A. 2000a. Kinetic characterization of the second step of group II intron splicing: Role of metal ions and the cleavage site $2^{\prime}-\mathrm{OH}$ in catalysis. Biochemistry 39: 12939-12952.

Gordon, P.M., Sontheimer, E.J., and Piccirilli, J.A. 2000b. Metal ion catalysis during the exon-ligation step of nuclear pre-mRNA splicing: Extending the parallels between the spliceosome and group II introns. RNA 6: 199-205.

Gordon, P.M., Fong, R., and Piccirilli, J.A. 2007. A second divalent metal ion in the group II intron reaction center. Chem. Biol. 14: $607-612$.

Guerrier-Takada, C., Gardiner, K., Marsh, T., Pace, N., and Altman, S. 1983. The RNA moiety of ribonuclease $P$ is the catalytic subunit of the enzyme. Cell 35: 849-857.

Gumbs, O.H., Padgett, R.A., and Dayie, K.T. 2006. Fluorescence and solution NMR study of the active site of a $160-\mathrm{kDa}$ group II intron ribozyme. RNA 12: 1693-1707.

Guo, F., Gooding, A.R., and Cech, T.R. 2004. Structure of the Tetrahymena ribozyme: Base triple sandwich and metal ion at the active site. Mol. Cell 16: 351-362.

Hilliker, A.K. and Staley, J.P. 2004. Multiple functions for the invariant AGC triad of U6 snRNA. RNA 10: 921-928.

Huppler, A., Nikstad, L.J., Allmann, A.M., Brow, D.A., and Butcher, S.E. 2002. Metal binding and base ionization in the U6 RNA intramolecular stem-loop structure. Nat. Struct. Biol. 9: 431435.

Jarrell, K.A., Dietrich, R.C., and Perlman, P.S. 1988. Group II intron domain 5 facilitates a trans-splicing reaction. Mol. Cell. Biol. 8: 2361-2366.

Konforti, B.B., Abramovitz, D.L., Duarte, C.M., Karpeisky, A., Beigelman, L., and Pyle, A.M. 1998. Ribozyme catalysis from the major groove of group II intron domain 5. Mol. Cell 1: 433-441.

Kruger, K., Grabowski, P.J., Zaug, A.J., Sands, J., Gottschling, D.E., and Cech, T.R. 1982. Self-splicing RNA: Autoexcision and autocyclization of the ribosomal RNA intervening sequence of Tetrahymena. Cell 31: 147-157.

Lu, J., Nogi, Y., and Takami, H. 2001. Oceanobacillus iheyensis gen. nov., sp. nov., a deep-sea extremely halotolerant and alkaliphilic species isolated from a depth of $1050 \mathrm{~m}$ on the Iheya Ridge. FEMS Microbiol. Lett. 205: 291-297.

Michel, F. and Dujon, B. 1983. Conservation of RNA secondary structures in two intron families including mitochondrial-, chloroplast- and nuclear-encoded members. EMBO J. 2: 33-38.

Peebles, C.L., Perlman, P.S., Mecklenburg, K.L., Petrillo, M.L., Tabor, J.H., Jarrell, K.A., and Cheng, H.L. 1986. A self-splicing RNA excises an intron lariat. Cell 44: 213-223.

Peebles, C.L., Zhang, M., Perlman, P.S., and Franzen, J.S. 1995. Catalytically critical nucleotide in domain 5 of a group II intron. Proc. Natl. Acad. Sci. 92: 4422-4426.

Pley, H.W., Flaherty, K.M., and McKay, D.B. 1994. Model for an RNA tertiary interaction from the structure of an intermolecular complex between a GAAA tetraloop and an RNA helix. Nature 372: 111-113.

Podar, M., Zhuo, J., Zhang, M., Franzen, J.S., Perlman, P.S., and Peebles, C.L. 1998. Domain 5 binds near a highly conserved dinucleotide in the joiner linking domains 2 and 3 of a group II intron. RNA 4: 151-166. 
Pyle, A.M. and Lambowitz, A.M. 2006. Group II introns: Ribozymes that splice RNA and invade DNA. In The RNA world, 3rd ed. (eds. R.F. Gesteland et al.), pp. 469-506. Cold Spring Harbor Laboratory Press, Cold Spring Harbor, NY.

Schmidt, U., Podar, M., Stahl, U., and Perlman, P.S. 1996. Mutations of the two-nucleotide bulge of D5 of a group II intron block splicing in vitro and in vivo: Phenotypes and suppressor mutations. RNA 11: 1161-1172.

Seetharaman, M., Eldho, N.V., Padgett, R.A., and Dayie, K.T. 2006. Structure of a self-splicing group II intron catalytic effector domain 5: Parallels with spliceosomal U6 RNA. RNA 12: 235247.

Shukla, G.C. and Padgett, R.A. 2002. A catalytically active group II intron domain 5 can function in the U12-dependent spliceosome. Mol. Cell 9: 1145-1150.

Sigel, R.K., Sashital, D.G., Abramovitz, D.L., Palmer, A.G., Butcher, S.E., and Pyle, A.M. 2004. Solution structure of domain 5 of a group II intron ribozyme reveals a new RNA motif. Nat. Struct. Mol. Biol. 11: 187-192.

Sontheimer, E.J., Gordon, P.M., and Piccirilli, J.A. 1999. Metal ion catalysis during group II intron self-splicing: Parallels with the spliceosome. Genes \& Dev. 13: 1729-1741.

Stahley, M.R. and Strobel, S.A. 2005. Structural evidence for a twometal-ion mechanism of group I intron splicing. Science 309: 1587-1590.

Stahley, M.R. and Strobel, S.A. 2006. RNA splicing: Group I intron crystal structures reveal the basis of splice site selection and metal ion catalysis. Curr. Opin. Struct. Biol. 16: 319-326.
Steitz, T.A. and Steitz, J.A. 1993. A general two-metal-ion mechanism for catalytic RNA. Proc. Natl. Acad. Sci. 90: 6498-6502.

Takaki, Y., Matsuki, A., Chee, G.J., and Takami, H. 2004. Identification and distribution of new insertion sequences in the genome of the extremely halotolerant and alkaliphilic Oceanobacillus iheyensis HTE831. DNA Res. 11: 233-245.

Takami, H., Takaki, Y., and Uchiyama, I. 2002. Genome sequence of Oceanobacillus iheyensis isolated from the Iheya Ridge and its unexpected adaptive capabilities to extreme environments. Nucleic Acids Res. 30: 3927-3935.

Toor, N., Keating, K.S., Taylor, S.D., and Pyle, A.M. 2008. Crystal structure of a self-spliced group II intron. Science 320: 77-82.

Uchimaru, T., Uebayasi, M., Tanabe, K., and Taira, K. 1993. Theoretical analyses on the role of $\mathrm{Mg}^{2+}$ ions in ribozyme reactions. FASEB J. 7: 137-142.

Valadkhan, S., Mohammadi, A., Wachtel, C., and Manley, J.L. 2007. Protein-free spliceosomal snRNAs catalyze a reaction that resembles the first step of splicing. RNA 13: 2300-2311.

van der Veen, R., Arnberg, A.C., van der Horst, G., Bonen, L., Tabak, H.F., and Grivell, L.A. 1986. Excised group II introns in yeast mitochondria are lariats and can be formed by self-splicing in vitro. Cell 44: 225-234.

Yean, S.L., Wuenschell, G., Termini, J., and Lin, R.J. 2000. Metal-ion coordination by U6 small nuclear RNA contributes to catalysis in the spliceosome. Nature 408: 881-884.

Zhang, L. and Doudna, J.A. 2002. Structural insights into group II intron catalysis and branch-site selection. Science 295: 20842088. 

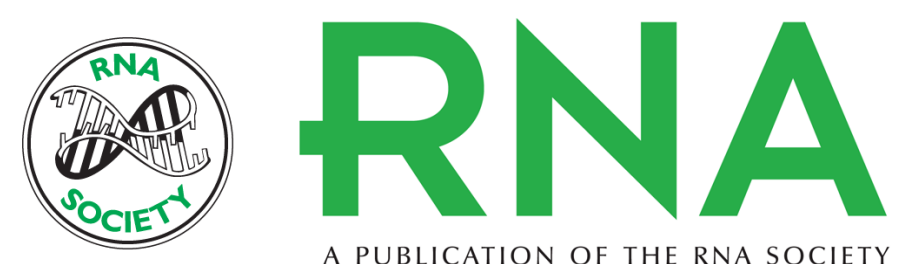

A PUBLICATION OF THE RNA SOCIETY

\section{A glimpse into the active site of a group II intron and maybe the spliceosome, too}

Kwaku T. Dayie and Richard A. Padgett

RNA 2008 14: 1697-1703 originally published online July 24, 2008

Access the most recent version at doi:10.1261/rna.1154408

$\begin{array}{ll}\text { References } & \begin{array}{l}\text { This article cites } 46 \text { articles, } 21 \text { of which can be accessed free at: } \\ \text { http://rnajournal.cshlp.org/content/14/9/1697.full.html\#ref-list-1 }\end{array}\end{array}$

License

Email Alerting Receive free email alerts when new articles cite this article - sign up in the box at the Service top right corner of the article or click here. 